The Journal of Animal \& Plant Sciences, 31(2): 2021, Page: 567-582

ISSN (print): 1018-7081; ISSN (online): 2309-8694

\title{
YEASTS IN FERMENTED FOOD AND KEFIR: IN VITRO CHARACTERIZATION OF PROBIOTIC TRAITS
}

\author{
Shih-An Hsu and Jui-Yu Chou* \\ Department of Biology, National Changhua University of Education, Changhua 500, Taiwan \\ "Corresponding author's Email: jackyjau@cc.ncue.edu.tw
}

\begin{abstract}
The probiotics are live microorganisms that, when administered in adequate amounts, confer a beneficial effect on host's health. Although most probiotics are bacteria, however, one yeast species (Saccharomyces boulardii) has also been characterized as probiotic. In this study, yeasts have been very important in the food industry and have several beneficial properties that bacteria do not have. In this study, yeast strains were isolated from fermented food and beverage. Various physiological features of the candidate probiotic isolates were preliminarily investigated, including bile salt and acid tolerance, cell surface hydrophobicity, autoaggregation, antioxidant activity, and $\beta$-galactosidase activity. We demonstrated several yeast strains have potential as probiotics. For example, Saccharomyces cerevisiae JYC2508 adapted well in a bile salt and acid tolerance test and also had good autoaggregation ability. Moreover, Kluyveromyces marxianus JYC2528 grew well in the bile salt and acid tolerance test and also had good performance with antioxidant activity, cell surface hydrophobicity, and $\beta$-galactosidase activity. The overall findings of this study showed that these yeast strains may offer promising probiotic traits relevant for further study.
\end{abstract}

Key words: autoaggregation, antioxidant activity, $\beta$-galactosidase activity, bile salt and acid tolerance, cell surface hydrophobicity, probiotic, yeast.

https://doi.org/10.36899/JAPS.2021.2.0245

Published online October 03,2020

\section{INTRODUCTION}

The intestinal digestive system is responsible for digesting food and absorbing nutrients. Intestinal health can affect overall health because most symbiotic microorganisms colonize the intestines (Long-Smith et al., 2020). Thus, numerous immunocytes are distributed in the intestinal wall. An unhealthy gut places considerable stress on the immune system, and may increase the body's susceptibility to infection from external pathogens (Kau et al., 2011). Thousands of microbial species are present in the intestine, and their total cell number is considerably higher than that needed by the human body (Eckburg et al., 2005). The behavior of these symbiotic microorganisms is closely related to the health of the intestines. Most microorganisms in a healthy human intestine are opportunistic; that is, they are typically non-pathogenic microorganisms that act as pathogens in certain circumstances. However, when pathogenic bacteria proliferate in the intestine and cause an imbalance in intestinal microflora, diseases may be triggered. Scientists have recently proposed that numerous physiological and mental diseases, such as irritable bowel syndrome, depression, anxiety disorder, autism, and chronic fatigue may be related to a patient's gut health (Cheung et al., 2019; Czerucka et al., 2007). The reason for this is that the number of nerve cells in the digestive system is second only to the number in the brain (Mayer, 2011). The concept of the intestinal digestive system and the symbiotic microbes within it affecting the brain and even human behavior is called the microbiomegut-brain axis (Heijtz et al., 2011). The connections between the brain and nerve cells are incomplete in germfree mice, which affects their behavioral patterns (Heijtz et al., 2011). Although it is unclear whether intestinal microbes affect the nervous system, maintaining probiotic populations in the gut is vital for human health.

Probiotics are defined as live microorganisms that confer a beneficial effect on a host's health when present in adequate numbers (FAO/WHO, 2001, 2002). Several conditions are necessary for a microbe to be considered probiotic: it must be innocuous (not causing damage or disease to its host), its activity and population should remain high during the shelf life of the product it is in, and it must be able to survive gastrointestinal (GI) transit (De Vrese and Schrezenmeir, 2008; Hill et al., 2014; Tripathi and Giri, 2014). Using multifunctional microorganisms as starter cultures with probiotic activity is a trend in food microbiology (Perricone et al., 2014; Terpou et al., 2019). People can improve their health by consuming foods containing probiotics as part of their daily diet. Therefore, evaluating the probiotic functions and properties of microorganisms in foods, such as the inhibition of pathogens (Binetti et al., 2013; Silva et al., 2011), antioxidant activity (Chen et al., 2010b), and $\beta$ galactosidase activity (Kippert, 1995) is imperative. Most probiotics comprise Lactobacillus spp. and Bifidobacterium spp. (De Vrese and Schrezenmeir 2008; 
Hill et al., 2014). However, the probiotic or beneficial potential of yeasts is usually ignored, despite being imperative and widely distributed in foods and beverages (Chen et al., 2010b; Diosma et al., 2014; Gil-Rodríguez et al., 2015). Saccharomyces boulardii is the only yeast species that has been recognized and characterized as a commercial probiotic (Czerucka and Rampal, 2002; Rima et al., 2012). Whether other yeast species or strains have probiotic characteristics warrants exploration (Binetti et al., 2013; Van der Aa Kühle et al., 2005).

Yeasts are vital in the production of numerous foods and beverages, such as wine, bread, kefir, and beer (Antunes and Aguiar, 2012; Moreira et al., 2011), and participate in the maturation process of some cheeses (Binetti et al., 2013). Yeasts are useful in the food industry and usually used in traditional food fermentations are generally recognized as safe. It is worth exploring the probiotic potential of yeasts for the following reasons. First, they have excellent resistance to antibacterial agents. This feature is imperative because some medical treatments combine probiotics and antibiotics for treating GI infections. Second, the genetic material of yeasts is not transferred to other microorganisms through conjugation or transformation (Czerucka et al., 2007). Antimicrobial resistance has become a critical public health problem. Thus, the major reason for using yeasts and antibiotics to treat patients is that, although yeasts exhibit antimicrobial resistance, they do not transfer drug resistance genes to other microorganisms. The transfer of genes between bacteria causes antimicrobial resistance. The mammalian GI tract produces a favorable environment for many bacterial species to transfer their genetic material (Salyers et al., 2004). Resistance genes can be transferred not only between resident intestinal microflora, but also transferred from bacterial probiotics (Temmerman et al., 2003; Mathur and Singh, 2005). Numerous researchers have suggested that commensal bacteria, including lactic bacteria, may act as reservoirs of antibiotics (Mathur and Singh, 2005). Yeasts have long been considered safe microbes (Diosma et al., 2014), with beneficial characteristics including competitiveness for nutrition, better cell adherence (because of their size and autoaggregation ability), and genetic material that is not transferred to commensal bacteria (Czerucka et al., 2007).

Microorganisms are subjected to numerous harsh environments as they pass through the human GI tract. For example, the $\mathrm{pH}$ in the stomach ranges from 2 to 5, which is harmful to most microorganisms. While the $\mathrm{pH}$ increases toward the distal part of the GI tract, the presence of aggressive intestinal fluids (e.g., bile and pancreatic juices) and the short transit time in the duodenum, creates a harsh environment for most microorganisms in the duodenum. Thus, the duodenum contains relatively few microbes. The presence of yeasts in this stressful environment can be explained by their resistance to $\mathrm{pH}$ variation (Czerucka et al., 2007). Most yeasts can grow at a $\mathrm{pH}$ of 3.0 , and some can tolerate highly acidic conditions ( $\mathrm{pH}$ 1.5) (Czerucka et al., 2007). Probiotics must adapt to the pressure of the GI tract caused by bile salts, organic acids, multiple digestive enzymes, and considerable variations in $\mathrm{pH}$. Thus, yeasts are good candidates as probiotics and numerous studies have shown that oxidative damage produced by free radicals, especially reactive oxygen species (ROS), causes many chronic diseases (e.g., osteoarthritis, rheumatoid arthritis, cardiovascular disease, and some tumors) (Ciafardini and Zullo 2020; De Vrese and Schrezenmeir, 2008; Kawagishi and Finkel, 2014; Valko et al., 2006). The risk of developing these diseases can be reduced by decreasing this oxidative damage (Serafini, 2006; Trotta et al., 2012). Studies on natural antioxidants have reported that yeasts and yeast extracts have antioxidant activity due to a wide range of substances (e.g., superoxide dismutase, catalase, oxygenated carotenoids, resveratrol, and octacosanol), and that (1-3)$\beta$-D-glucan and other $\beta$-glucans, which constitute the cell wall of yeasts, have imperative functions (Abbas, 2006; Jaehrig et al., 2007). Moreover, cell surface hydrophobicity and autoaggregation are considered to be correlated to the retention capacity of microorganisms in the intestine (de Lima et al., 2017). Because yeast species are larger than other microorganisms, they easily attach to the intestinal wall. Mannose is one of the components in the cell wall of yeasts, which has excellent viscosity and enables yeasts to aggregate quickly (Ofek and Beachey, 1978). Most food in the intestine is in a mobile phase and can remove the microorganisms on the intestinal wall through intestinal motility. Microorganisms with good cell surface hydrophobicity are less likely to be removed. Therefore, cell surface hydrophobicity is also vital for maintaining microbes in the intestine.

Probiotics are beneficial for promoting the gut absorption efficiency of their host because they secret enzymes to improve the utilization and absorption of nutrients along the digestive tract. For example, lactose is hydrolyzed into glucose and galactose by $\beta$-galactosidase, which are then transported across the brush border membrane of epithelial cells into the cytosol (Saqib et al., 2017). When undigested lactose is transported to the small intestine and is fermented by colonic bacteria, hydrogen gas is released and lactose indigestion symptoms occur (Hertzler and Clancy, 2003). Probiotics that have $\beta$-galactosidase activity are imperative because they can avoid discomfort during intestinal fermentation after consumption of dairy products (Sourabh et al., 2011). This enzyme is also utilized to avoid lactose crystallization, increase the solubility of milk products, and solve the problems associated with whey utilization and whey disposal, which can cause pollution 
(Rosenberg, 2006). In this study, we isolated yeast strains from fermented food and beverage and evaluated their probiotic potential. Probiotic potential was assessed using several experiments, namely the ability of the strains to grow at $37^{\circ} \mathrm{C}$ and their survival rate in bile salt and acid, as well as their autoaggregation activity, cell surface hydrophobicity, antioxidant activity, and $\beta$-galactosidase activity.

\section{MATERIALS AND METHODS}

Yeast strain isolation, identification, and culture conditions: In this study, yeast strains were isolated from various fermented foods and beverages, milk kefir, water kefir, and kombucha. The samples were serially diluted with sterile deionized water and then spread uniformly on yeast extract peptone dextrose (YPD) agar plates (1\% yeast extract, $2 \%$ peptone, $2 \%$ dextrose, and $2 \%$ agar) supplemented with $0.3 \%$ lactic acid by using sterile glass beads. Yeast colonies of different morphologies were selected and purified by streaking them on YPD agar plates. Purified yeast cultures $(1 \mathrm{~mL})$ were mixed with $200 \mu \mathrm{L}$ of glycerol $(\geq 99.5 \%)$ and stored at $-80{ }^{\circ} \mathrm{C}$. The purified yeast was refreshed in YPD medium and incubated at $28{ }^{\circ} \mathrm{C}$ for $3 \mathrm{~h}$. Yeast cultures $(1 \mathrm{~mL})$ were transferred to a $1.5-\mathrm{mL}$ centrifuge tube and centrifuged at $13000 \mathrm{rpm}$ for $1 \mathrm{~min}$. The supernatant was discarded and the cell pellet was suspended in $200 \mu \mathrm{L}$ of lysis buffer (2\% Triton X-100, 1\% sodium dodecyl sulfate, $100 \mathrm{mM}$ sodium chloride, and $10 \mathrm{mM}$ Tris [pH 8.0], and $1 \mathrm{mM}$ ethylenediaminetetraacetic acid), after which $200 \mu \mathrm{L}$ of phenol-chloroform-isoamyl alcohol (25:24:1; isoamyl alcohol is optional) and 0.3 -g acid-washed glass beads $(0.45-0.52 \mathrm{~mm})$ were added and mixed gently. The samples were vortexed at $2500 \mathrm{rpm}$ for $10 \mathrm{~min}$ to disrupt the cells and then were centrifuged at $13000 \mathrm{rpm}$ for 5 min. The aqueous layer of each sample was transferred to a new tube with $400 \mu \mathrm{L}$ of $95 \%$ ethanol and $16 \mu \mathrm{L}$ of 3 $\mathrm{M}$ sodium acetate. The samples were vortexed again, stored at $-20{ }^{\circ} \mathrm{C}$ for $15 \mathrm{~min}$, and then centrifuged at $13000 \mathrm{rpm}$ for $5 \mathrm{~min}$ at $4{ }^{\circ} \mathrm{C}$. The pellets were washed with $300 \mu \mathrm{L}$ of $70 \%$ ethanol, and the tubes were aspirated with air for $3 \mathrm{~h}$ to dry the pellets. Finally, genomic deoxyribonucleic acid (DNA) from each sample was suspended in $50 \mu \mathrm{L}$ of sterile water.

The large subunit (LSU) rDNA D1/D2 domain and the internal transcribed spacer (ITS) region were amplified were amplified with the universal primers ITS1 (5'-TCCGTAGGTGAACCTGCG-3') and NL-4 (5'GGTCCGTGTTTCAAGACGG-3') through polymerase chain reaction (White et al., 1990; Kurtzman and Robnett, 1997). Samples were sent to Tri-I Biotech, Inc. for DNA sequencing. The sequences obtained in this study (ITS regions, and partial LSU) were identified by searching databases using the BLAST sequence analysis tool (http://www.ncbi nlm.nih.gov/BLAST/) on the
National Center for Biotechnology Information's homepage. The sequences were compared with the default setting using nucleotide- nucleotide BLAST (blastn). Yeast identification was based on sequence differences; yeast strains with a $\leq 1 \%$ sequence difference are considered conspecific species. Nucleotide sequences of the studied strains deposited in the GenBank are given in Table 1.

Bile salt and acid tolerance: The samples were cultured in YPD medium overnight at $28{ }^{\circ} \mathrm{C}$ and were refreshed in the same medium for $3 \mathrm{~h}$ to let the cells into the log phase. Yeast cultures were quantified using a spectrophotometer (Unico 1200 Spectrophotometer, USA) at $660 \mathrm{~nm}$. The cell numbers were all adjusted to $1.28 \times 10^{6} / \mathrm{mL}$ according to the optical density (OD) of the yeast strains. The samples were washed twice with $0.9 \% \mathrm{NaCl}$ solution and then were transferred to YPD medium at $\mathrm{pH} 3$ (adjusted with $6 \mathrm{M} \mathrm{HCl}$ ) and incubated at $37{ }^{\circ} \mathrm{C}$ for $2 \mathrm{~h}$. Next, $1 \mathrm{~mL}$ of culture was harvested (13000 rpm, $1 \mathrm{~min}$ ), washed twice with $0.9 \% \mathrm{NaCl}$ solution, and resuspended in YPD medium with $3.0 \mathrm{~g} / \mathrm{L}$ bile salt (Sigma-Aldrich). The samples were incubated at $37{ }^{\circ} \mathrm{C}$. The optical density at a wavelength of $600 \mathrm{~nm}$ $\left(\mathrm{OD}_{660}\right)$ was measured after $3 \mathrm{~h}$ and $24 \mathrm{~h}$ of incubation (Ogunremi et al., 2015).

Autoaggregation and settlement assay: The screening of the autoaggregation ability and surface hydrophobicity was performed to identify the adherent ability of the yeast strains. The samples were cultured in YPD medium overnight at $28{ }^{\circ} \mathrm{C}$ and were refreshed in the same medium for $3 \mathrm{~h}$. The cell numbers were adjusted to 1.85 $\times 10^{7} / \mathrm{mL}$ according to the $\mathrm{OD}_{660}$. The samples were washed twice with phosphate buffered saline solution (PBS, pH 7.4, Sigma-Aldrich), and the cells were harvested by centrifugation and resuspended in the same solution. In autoaggregation (sometimes also called autoagglutination or flocculation), yeast cells of the same type form multicellular clumps that easily settle at the bottom of culture tubes. Thus, the $\mathrm{OD}_{660}$ was measured after incubation at $37^{\circ} \mathrm{C}$ after $0,2,4$, and $24 \mathrm{~h}$ to analyze the autoaggregation and settlement ability. The percentage of aggregation (\%A) was calculated according to the following equation:

$\% \mathrm{~A}_{\mathrm{t}}=\left[1-\left(\mathrm{OD}_{\mathrm{t}}-\mathrm{OD}_{\mathrm{i}}\right)\right] \times 100$, where $\mathrm{OD}_{\mathrm{i}}$ is the initial optical density of the microbial suspension and $\mathrm{OD}_{\mathrm{t}}$ is the optical density at time t (Ogunremi et al., 2015; RomeroLuna et al., 2019).

Cell surface hydrophobicity assay: The hydrophobicity of the yeast strains was evaluated following the classification in Rosenberg et al. (1980). Cell surface hydrophobicity was assessed using microbial adhesion to hydrocarbons. Thus, the microbial adhesion to hydrocarbon (xylene) was used to analyze the cell surface hydrophobicity of the yeast strains. Yeast strains were 
refreshed in YPD medium overnight at $28{ }^{\circ} \mathrm{C}$ and incubated at $37{ }^{\circ} \mathrm{C}$ for $8 \mathrm{~h}$. The cell numbers were adjusted to $1.85 \times 10^{7} / \mathrm{mL}$ according to the $\mathrm{OD}_{660}$. The samples were washed with PBS buffer, and the cells were harvested by centrifugation and resuspended in the same buffer. The $\mathrm{OD}_{660}$ was measured using a spectrophotometer to confirm the cell numbers $\left(\mathrm{OD}_{1}\right)$. Next, $0.8 \mathrm{~mL}$ of xylene was added to $1.2 \mathrm{~mL}$ of the yeast suspensions, and then the mix was vortexed for $60 \mathrm{~s}$ and rested for $2 \mathrm{~h}$ at $37{ }^{\circ} \mathrm{C}$. Next, draw the aqueous phase carefully and the $\mathrm{OD}_{660}\left(\mathrm{OD}_{2}\right)$ was measured. The hydrophobicity index (HPBI) was calculated according to the following equation: $\% \mathrm{HPBI}=\left[\left(\mathrm{OD}_{1}-\mathrm{OD}_{2}\right) / \mathrm{OD}_{1}\right] \times$ 100 (de Lima et al., 2017).

Antioxidant activity: The percentage reduction of the 1,1-diphenyl-2-picrylhydrazyl (DPPH, Sigma-Aldrich) radical was used to evaluate the antioxidant activity of the yeast strains (Chen et al., 2010b). Yeast strains were cultured in YPD medium overnight at $28{ }^{\circ} \mathrm{C}$ and refreshed in the same medium for $3 \mathrm{~h}$. The cell numbers were adjusted to $1.85 \times 10^{7} / \mathrm{mL}$ according to the $\mathrm{OD}_{660}$. The samples were washed once with $0.9 \% \mathrm{NaCl}$ solution and then the cells were transferred to $400 \mu \mathrm{L}$ of PBS solution. The cell suspension $(400 \mu \mathrm{L})$ was mixed with $500 \mu \mathrm{L}$ of $0.2 \mathrm{mM}$ DPPH solution (dissolved in methanol). The mixture was vortexed and then incubated for $30 \mathrm{~min}$ at room temperature in darkness. The reaction tubes were centrifuged (13000 rpm, $1 \mathrm{~min}$ ) and $200 \mu \mathrm{L}$ of the supernatant was transferred to 96 -well plates to measure the optical density at $517 \mathrm{~nm}$ by using a microplate reader (Thermo Scientific Multiskan GO, USA). The radical scavenging activity was calculated as a percentage of DPPH discoloration using the following equation:

$\left[\left(1-\mathrm{OD}_{517 \text { (sample) }} / \mathrm{OD}_{517 \text { (blank) }}\right] \times 100 \%\right.$

To quantify the antioxidant activity, we also assessed the Trolox equivalent antioxidant capacity of each strain by using a solution with $1 \mathrm{mM}$ 6-hydroxy2,5,7,8-tetramethylchroman-2-carboxylic acid (Trolox, Sigma-Aldrich) dissolved in methanol (Ogunremi et al., 2015). Trolox was diluted to different concentrations ( 0 $80 \mu \mathrm{M})$ by using methanol, and $400 \mu \mathrm{L}$ of each concentration of Trolox was mixed with $500 \mu \mathrm{L}$ of 0.2 $\mathrm{mM}$ DPPH and incubated for $30 \mathrm{~min}$ at room temperature in darkness. Finally, $200 \mu \mathrm{L}$ of the mixture was transferred to 96-well plates to measure the optical density at $517 \mathrm{~nm}$. In doing so, the scavenging ratio of the sample and Trolox on DPPH at the same time was tested, and then a suitable range of concentration of the Trolox and its scavenging percentage was found. Thus, a linear regression equation between the Trolox concentration and its scavenging percentage was built, and the Trolox equivalent antioxidant capacity was calculated through the equation, according to the scavenging percentage of the sample solution to the DPPH radical solution.

$\boldsymbol{\beta}$-galactosidase activity: To evaluate the $\beta$-galactosidase activity, the protocol described by Kippert (1995) was used with some modifications. Yeast strains were cultured in YPD medium overnight at $28{ }^{\circ} \mathrm{C}$ and were refreshed in the same medium for $3 \mathrm{~h}$. The cell numbers were adjusted to $1.85 \times 10^{7} / \mathrm{mL}$ according to the $\mathrm{OD}_{660}$. The samples were washed with PBS buffer and centrifuged, and then $400 \mu \mathrm{L}$ of $\mathrm{Z}$ buffer $(0.06 \mathrm{M}$ $\mathrm{Na}_{2} \mathrm{HPO}_{4} .7 \mathrm{H}_{2} \mathrm{O}, 0.04 \mathrm{M} \mathrm{NaH} \mathrm{PO}_{4} \cdot \mathrm{H}_{2} \mathrm{O}, 0.01 \mathrm{M} \mathrm{KCl}$, $0.001 \mathrm{M} \mathrm{MgSO}_{4}$, and $0.05 \mathrm{M} \beta$-mercaptoethanol) and $200 \mu \mathrm{L}$ of lysis buffer were added. The samples were mixed and stored at $-80{ }^{\circ} \mathrm{C}$ for $90 \mathrm{~min}$. After the samples were thawed at room temperature for $20 \mathrm{~min}, 200 \mu \mathrm{L}$ was transferred to a new tube and the same volume of $3 \mathrm{mM}$ o-nitrophenyl- $\beta$-D-galactopyranoside (Sigma-Aldrich) was added. The tube was briefly shaken by hand and was incubated for $30 \mathrm{~min}$ at $37^{\circ} \mathrm{C}$. The reaction was stopped by adding $800 \mu \mathrm{L}$ of $0.1 \mathrm{M} \mathrm{Na}_{2} \mathrm{CO}_{3}$. The mixture was then centrifuged $(13000 \mathrm{rpm}, 1 \mathrm{~min})$ and $200 \mu \mathrm{L}$ of the supernatant were transferred to 96 -well plates to measure the optical density at $420 \mathrm{~nm}$. A standard curve of onitro-phenol (ONP, Acros-Organics) was obtained using known concentrations of ONP, from 0.05 to $2 \mathrm{mmol} / \mathrm{mL}$ at intervals of $0.05 \mathrm{mmol} / \mathrm{mL}$. The concentration of ONP was calculated using a standard curve: $\mathrm{y}=1.3997 \mathrm{x}+$ $0.0449\left(R^{2}=0.998\right)$. One unit of enzyme activity was defined as the amount of enzyme that liberated $1 \mu \mathrm{M}$ of ONP per min at $37{ }^{\circ} \mathrm{C}$. Enzyme activity was computed in Miller units according to the following equation:

Miller units of galactosidase activity $=1000 \times$ $\mathrm{OD}_{420} /$ time $(\mathrm{min}) \times$ volume $(\mathrm{mL}) \times \mathrm{OD}_{660}($ Miller, 1972 ; Miller et al., 1992).

Statistical analysis: Two biological replicates (three technical replicates per biological replicate) were designed and conducted of each assay abovementioned. A significant association between the biological replicates by calculating Spearman's rank correlation coefficient $(\mathrm{rs})$ is indicated by $\mathrm{P}<0.05$. The figures shown here are for only one of the two biological replicates used in this work. Data are expressed as mean \pm standard deviation (SD). The significance of differences between groups was determined using Student $\mathrm{t}$ tests and analyses of variance. $\mathrm{P}<0.05$ was considered statistically significant. ${ }^{*} \mathrm{P}<0.05$; $* * \mathrm{P}<0.01$.

\section{RESULTS}

Yeast strain isolation: In this study, 59 yeast strains were isolated from fermented foods and beverages, milk kefir, water kefir, and kombucha (26 strains from fermented foods and beverages, 3 strains from water kefir, 27 strains from milk kefir, and 3 strains from kombucha). These yeast strains represent 18 species 
(Table 1) in the genera Dekkera (1 strain), Hanseniaspora (2 strains), Kazachstania (14 strains), Kluyveromyces (9 strains), Kwoniella (1 strain), Pichia (1 strain), Saccharomycopsis (6 strains), Saccharomyces (19 strains), Torulaspora (1 strain), Wickerhamomyces (1 strain), and Zygosaccharomyces (4 strains). The details of their pathogenic or nonpathogenic nature were confirmed through a literature search. Even though further research on the pathogenicity and virulence of these candidates is needed. Saccharomyces boulardii was purchased and isolated from a probiotic supplement (Now Foods, USA) and was used as the control group of each experiment.

Bile salt and acid tolerance: All the yeast strains survived and grew well in the YPD medium at $\mathrm{pH} 3$ at 37 ${ }^{\circ} \mathrm{C}$ for $2 \mathrm{~h}$ (Fig. 1). Of the 60 strains analyzed, 9 strains (15\%) exhibited growth $24 \mathrm{~h}$ after they were transferred to YPD with $0.3 \%$ bile salt (Fig. 2). The yeast strains that adapted well to the YPD medium containing bile salt were Saccharomyces cerevisiae JYC2507 and JYC2508, Saccharomycopsis fibuligera JYC2511 and JYC2523, and Pichia kudriavzevii JYC2527. These strains showed obvious cell growth after $24 \mathrm{~h}(\mathrm{OD}>1)$. The strains that survived but where the growth rate was inhibited in the YPD medium containing bile salt were $S$. fibuligera JYC2516, Kluyveromyces marxianus JYC2528, $S$. cerevisiae JYC2542, and Wickerhamomyces anomalus JYC2560. These strains showed a small amount of growth after $24 \mathrm{~h}(\mathrm{OD}>0.1)$. Overall, 30 strains $(50 \%)$ endured the YPD medium containing bile salt for at least $3 \mathrm{~h}$. Cell growth was observed in these strains for $3 \mathrm{~h}$, but growth slowed or stopped at $24 \mathrm{~h}$. Of the remaining strains that could not endure the YPD medium containing bile salt, their $\mathrm{OD}_{660}$ gradually decreased; thus, the OD values of most of these strains decreased to a negative value. The reason for these cases was that the bile salt is consumed to emulsifying lipid and cause cell lysis. In this experiment, 39 strains (66\%) exhibited a better survival rate than that of $S$. boulardii.

Autoaggregation: The autoaggregation percentages obtained for all the yeast strains were highest at $24 \mathrm{~h}$ (Fig. 3 ). At $2 \mathrm{~h}$, the autoaggregation percentages showed a high level of variability. Most of the strains displayed fast autoaggregation within the first $4 \mathrm{~h}$ of incubation. As shown in Figure 3, high aggregation percentages usually occurred between 2 and 4 h (in 57 of the 60 strains, 95\%). The remaining three strains showed a negative value between 0 and $2 \mathrm{~h}$ and 2 and $4 \mathrm{~h}$, which became positive between $4 \mathrm{~h}$ and $24 \mathrm{~h}$. The strains with excessively low autoaggregation performance in the first $4 \mathrm{~h}$ belonged to $S$. fibuligera. Therefore, using the spectrophotometer, we observed that the density of cellular aggregates and the optical density were higher than that in the previous time point.

Cell surface hydrophobicity: Most of the tested strains showed moderate to high hydrophobicity (Fig. 4): 23 strains $(38.3 \%)$ showed a moderate hydrophobicity rate between $25 \%$ and $50 \%$ and 21 strains (35\%) showed a high hydrophobicity rate over $50 \%$. K. marxianus JYC2557 showed the highest hydrophobicity $(79.4 \% \pm$ $4.9 \%$ ), whereas $S$. cerevisiae JYC2535 showed the lowest $(6.61 \% \pm 2.68 \%)$. Overall, 52 strains $(86.4 \%)$ had a cell surface hydrophobicity higher than that of $S$. boulardii.

Antioxidant activity: The antioxidant capacities of the strains varied (Fig. 5). Among the 60 yeast strains analyzed, 3 strains (5\%) showed low antioxidant activity (with a DPPH scavenging percentage under 20\%), 6 strains (10\%) showed moderate activity (between 20\% and 30\%), 12 strains (20\%) showed good activity (between 30\% and 40\%), 20 strains (33.3\%) exhibited very good activity (between $40 \%$ and $50 \%$ ), and 19 strains (31.6\%) displayed excellent activity (over 50\%) (Table 2). Hanseniaspora osmophila JYC2504 produced the lowest value $(18.41 \% \pm 5.81 \%)$, whereas $S$. fibuligera JYC2512 (70.76\% $\pm 2.07 \%)$ and JYC2519 (70.59\% \pm $0.98 \%$ ) produced the two highest values. The antioxidant activity was also measured as Trolox equivalents (TE, $\mu \mathrm{M})$, and the results showed a range between $30.4 \pm 5.4$ TE (for H. osmophila JYC2504) and 158.2 \pm 5.4 TE (for S. fibuligera JYC2512). Overall, 55 strains (91.5\%) had a better antioxidant ability than that of $S$. boulardii $(25.3 \%$ $\pm 3.58 \%, 40.6 \pm 4.8 \mathrm{TE})$.

$\boldsymbol{\beta}$-galactosidase activity: Most of the strains in this study did not produce $\beta$-galactosidase activity. Of the 60 strains analyzed, only 10 strains $(16.7 \%)$ showed $\beta$-galactosidase activity (Fig. 6). The strains that showed high to low $\beta$ galactosidase activities, Kazachstania turicensis JYC2529 (17.97 $\pm 0.08 \mathrm{U} / \mathrm{mL} ; 113.24 \pm 0.53$ Miller units), K. marxianus JYC2528 (15.97 $\pm 0.53 \mathrm{U} / \mathrm{mL}$; $119.23 \pm 3.72$ Miller units), $K$. marxianus JYC2557 (14.43 $\pm 0.7 \mathrm{U} / \mathrm{mL} ; 108.47 \pm 4.87$ Miller units), Kazachstania servazzii JYC2565 (9.33 $\pm 0.87 \mathrm{U} / \mathrm{mL}$; $72.76 \pm 6.07$ Miller units), K. marxianus JYC2569 (8.37 $\pm 0.56 \mathrm{U} / \mathrm{mL} ; 66.09 \pm 3.92$ Miller units), $K$. marxianus JYC2575 (6.88 $\pm 1.23 \mathrm{U} / \mathrm{mL} ; 55.64 \pm 8.64$ Miller units $)$, K. marxianus JYC2578 (6.43 $\pm 0.4 \mathrm{U} / \mathrm{mL} ; 52.45 \pm 2.78$ Miller units), K. marxianus JYC2563 (5.36 $\pm 1.01 \mathrm{U} / \mathrm{mL}$; $44.99 \pm 7.05$ Miller units), K. marxianus JYC2567 (0.85 $\pm 0.38 \mathrm{U} / \mathrm{mL} ; 13.46 \pm 2.66$ Miller units), and $K$. marxianus JYC2576 $(0.58 \pm 0.14 \mathrm{U} / \mathrm{mL} ; 11.54 \pm 1.00$ Miller units). 


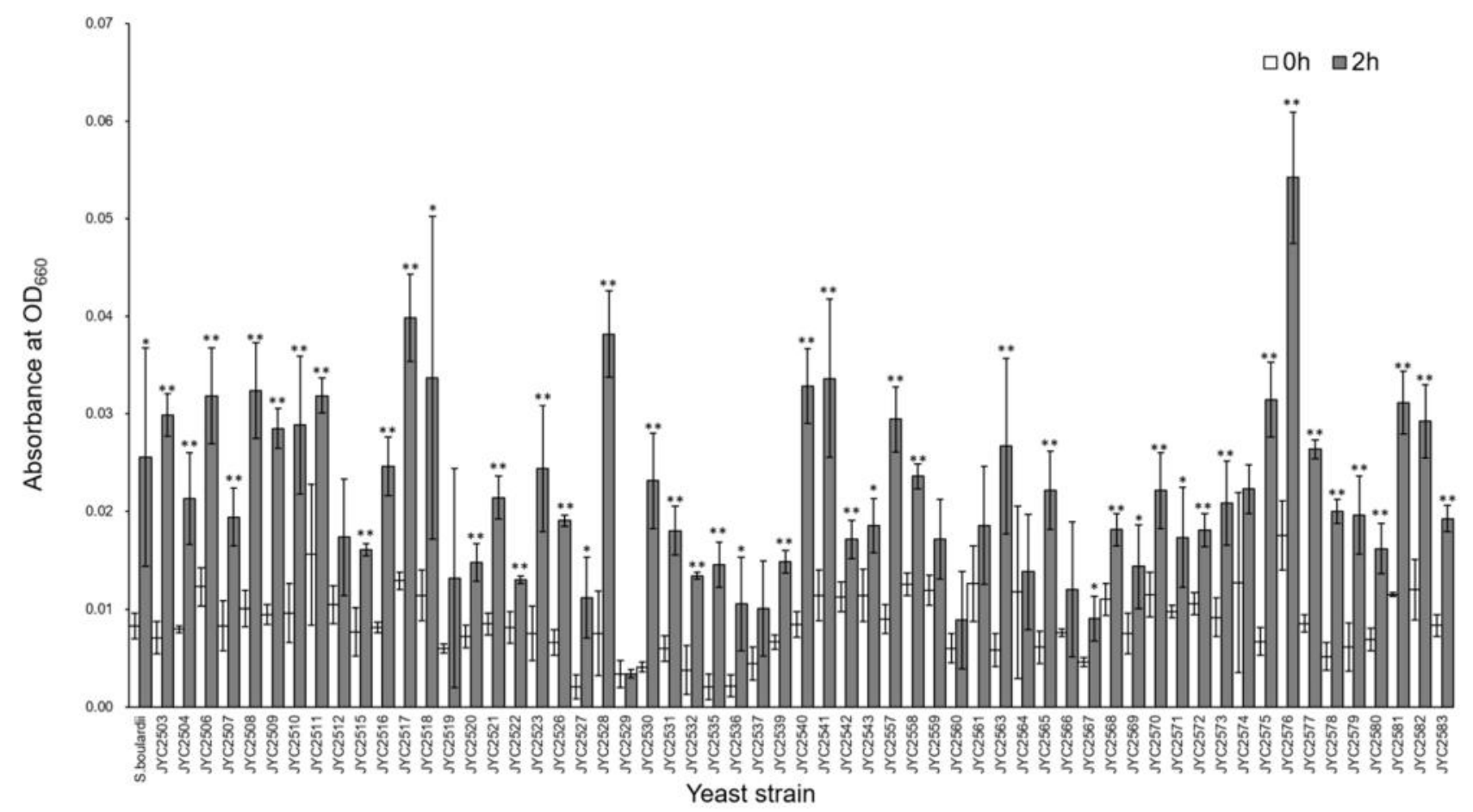

Fig. 1. Growth of yeast strains in YPD medium (pH 3) after $0 \mathrm{~h}$ (white) and $2 \mathrm{~h}$ (grey). The significance of differences between groups $(0 \mathrm{~h}$ and $2 \mathrm{~h}$ ) was determined using Student $\mathrm{t}$ tests and analyses of variance. $\mathrm{P}$ $<0.05$ was considered statistically significant. $* * P<0.01$. The experiments were repeated twice with similar results.

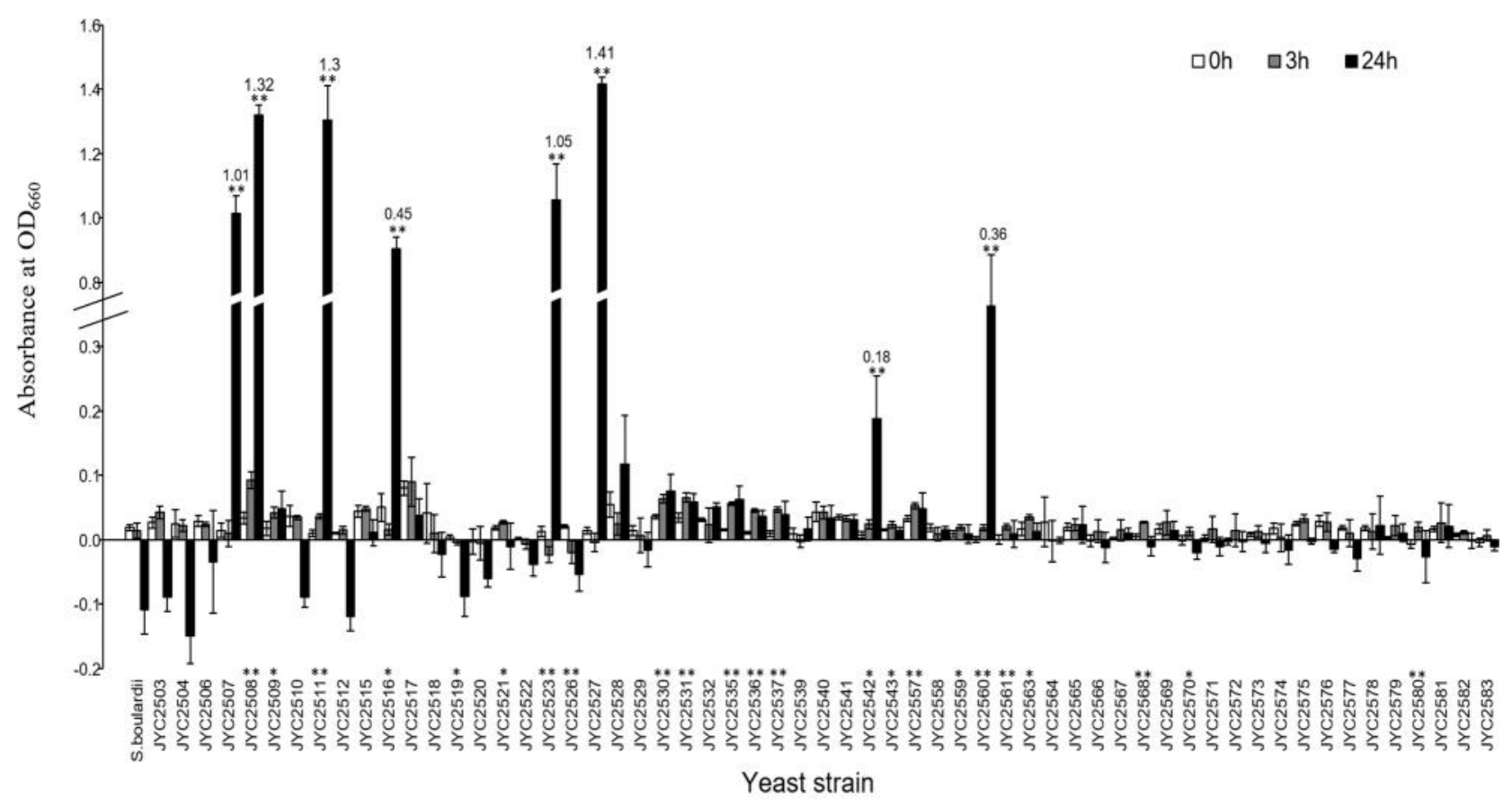

Fig. 2. Growth of yeast strains in YPD medium (0.3\% bile salt) after $0 \mathrm{~h}$ (white), $3 \mathrm{~h}$ (grey), and $24 \mathrm{~h}$ (black). The significance of differences between groups $(0 \mathrm{~h}$ and $3 \mathrm{~h}$, above the strain name; $3 \mathrm{~h}$ and $24 \mathrm{~h}$, above the columns) was determined using Student $t$ tests and analyses of variance. $P<0.05$ was considered statistically significant. $* * \mathrm{P}<0.01$. The experiments were repeated twice with similar results. 


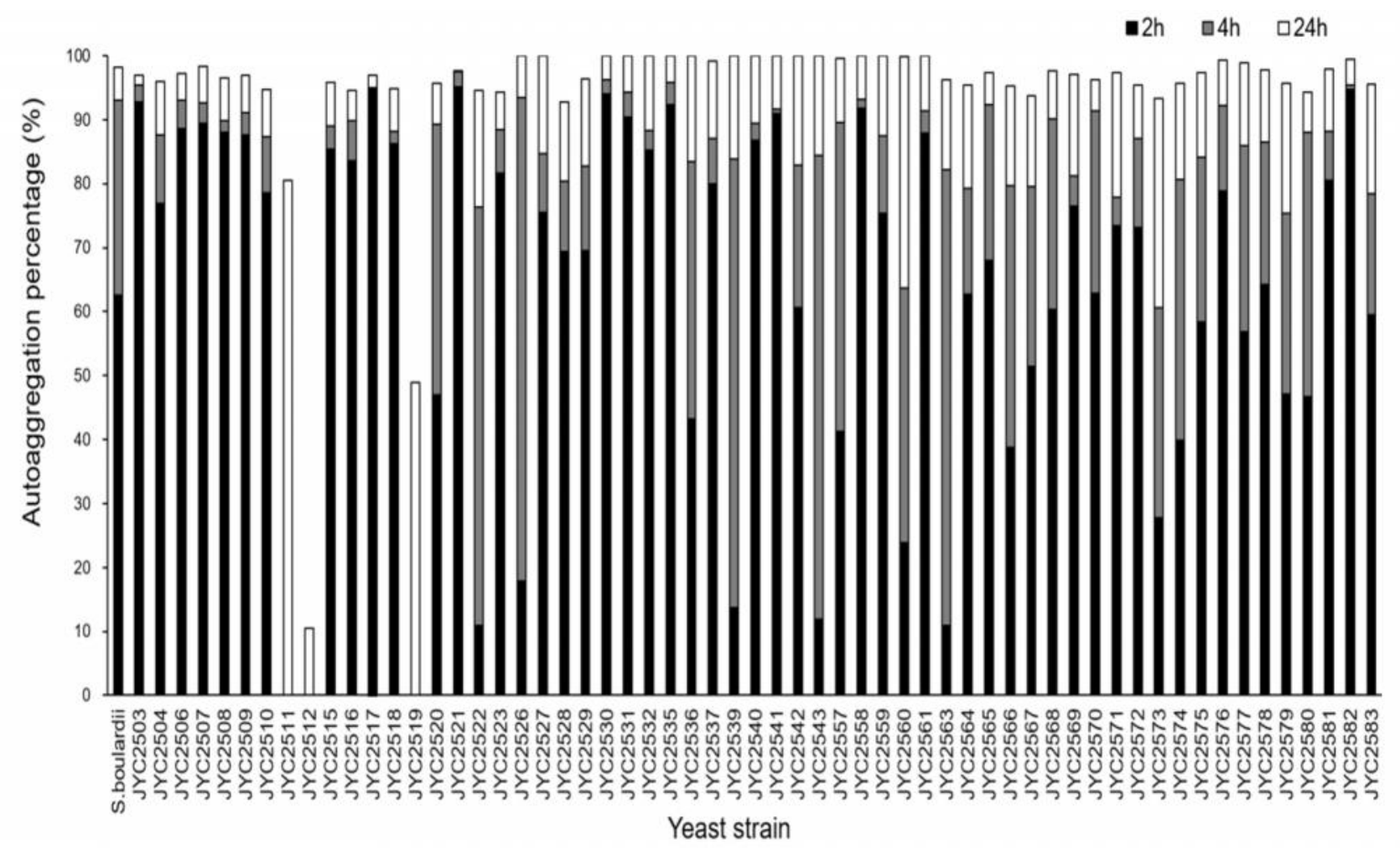

Fig. 3. Autoaggregation percentages of yeasts after $2 \mathrm{~h}$ (black), $4 \mathrm{~h}$ (grey), and $24 \mathrm{~h}$ (white).

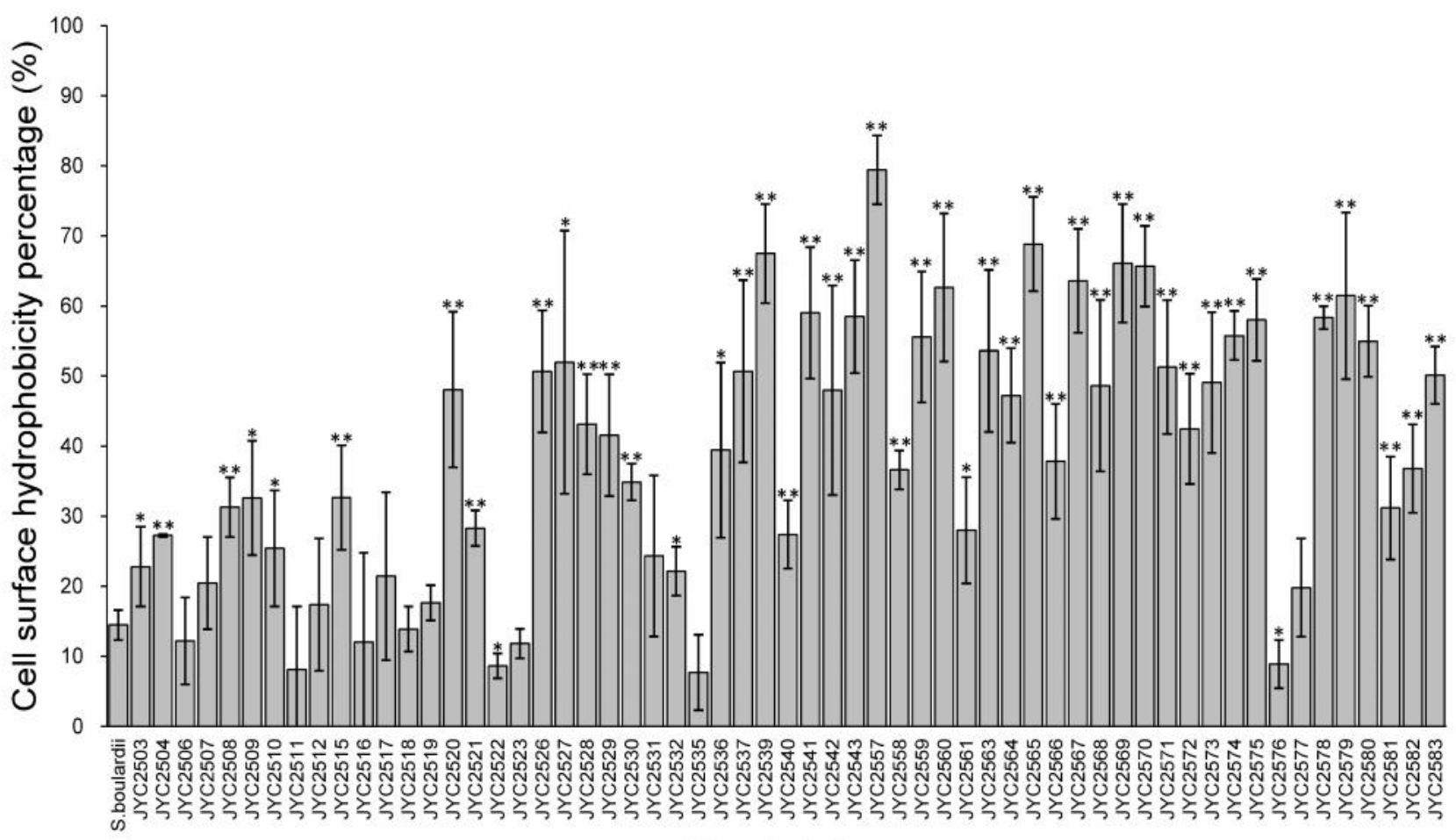

Yeast strain

Fig. 4. Cell surface hydrophobicity percentage of yeast strains. The significance of differences between groups (Saccharomyces boulardii and each yeast isolated) was determined using Student $t$ tests and analyses of variance. $P<0.05$ was considered statistically significant. ${ }^{* *} \mathrm{P}<0.01$. The experiments were repeated twice with similar results. 


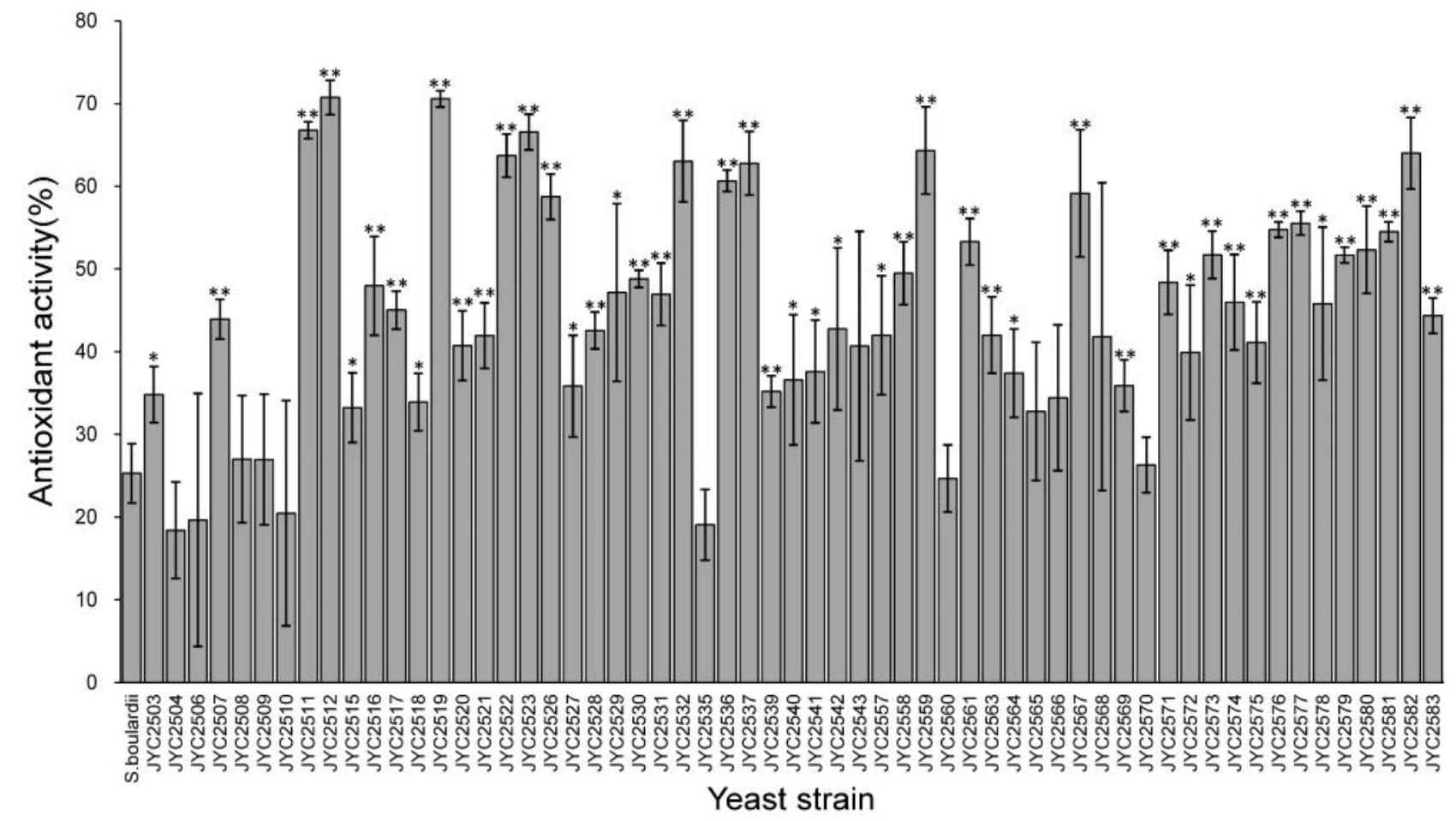

Fig. 5. Antioxidant activity percentage of yeast strains. The significance of differences between groups (Saccharomyces boulardii and each yeast isolated) was determined using Student tests and analyses of variance. $P<0.05$ was considered statistically significant. $* * P<0.01$. The experiments were repeated twice with similar results.

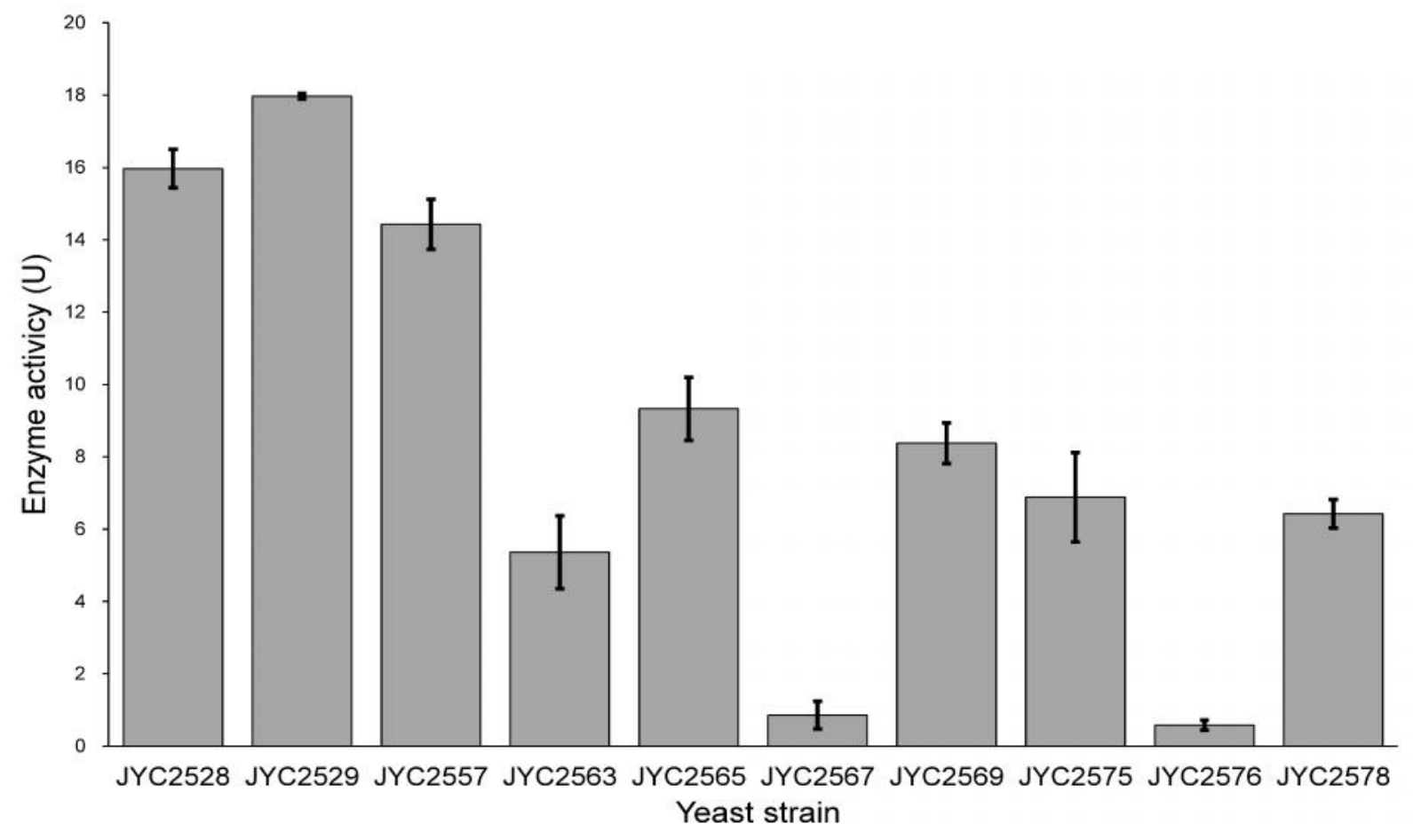

Fig. 6. $\beta$-galactosidase activity of yeast strains. $1 \mathrm{U}$ is equivalent to ONP production of $1 \mu \mathrm{M} / \mathrm{min}$. 
Table 1. Yeast species studied, number of strains belonging to each species, source of isolation, and origin.

\begin{tabular}{|c|c|c|c|}
\hline Species & Strains & $\begin{array}{l}\text { Accession } \\
\text { no. }\end{array}$ & Origin \\
\hline Dekkera bruxellensis & JYC2537 & MK044031 & kombucha; Taiwan \\
\hline Hanseniaspora osmophila & JYC2504 & MK044002 & fermented vinegar; Taiwan \\
\hline Hanseniaspora valbyensis & JYC2522 & MK044019 & water kefir; Germany \\
\hline Kazachstania exigua & JYC2539 & MK044033 & rice wine; Taiwan \\
\hline \multirow[t]{11}{*}{ Kazachstania servazzii } & JYC2564 & MK044044 & milk kefir; Taiwan \\
\hline & JYC2579 & MK044059 & milk kefir; Taiwan \\
\hline & JYC2565 & MK044045 & milk kefir; Germany \\
\hline & JYC2568 & MK044048 & milk kefir; Germany \\
\hline & JYC2570 & MK044050 & milk kefir; Germany \\
\hline & JYC2571 & MK044051 & milk kefir; Germany \\
\hline & JYC2572 & MK044052 & milk kefir; Germany \\
\hline & JYC2573 & MK044053 & milk kefir; America \\
\hline & JYC2574 & MK044054 & milk kefir; America \\
\hline & JYC2580 & MK044060 & milk kefir; Caucasus \\
\hline & JYC2583 & MK044063 & milk kefir; Tibet \\
\hline \multirow[t]{2}{*}{ Kazachstania turicensis } & JYC2529 & MK044026 & milk kefir; Taiwan \\
\hline & JYC2559 & MK044040 & milk kefir; Taiwan \\
\hline \multirow[t]{9}{*}{ Kluyveromyces marxianus } & JYC2528 & MK044025 & milk kefir; Taiwan \\
\hline & JYC2557 & MK044038 & milk kefir; Taiwan \\
\hline & JYC2563 & MK044043 & milk kefir; Taiwan \\
\hline & JYC2578 & MK044058 & milk kefir; Taiwan \\
\hline & JYC2566 & MK044046 & milk kefir; Germany \\
\hline & JYC2567 & MK044047 & milk kefir; Germany \\
\hline & JYC2569 & MK044049 & milk kefir; Germany \\
\hline & JYC2575 & MK044055 & milk kefir; Israel \\
\hline & JYC2576 & MK044056 & milk kefir; Israel \\
\hline Kwoniella shandongensis & JYC2515 & MK044012 & wine lees; China \\
\hline Pichia kudriavzevii & JYC2527 & MK044024 & milk kefir; Taiwan \\
\hline Saccharomyces boulardii & I-3799 & & (purchased from New Foods, USA) \\
\hline \multirow[t]{19}{*}{ Saccharomyces cerevisiae } & JYC2503 & MK044001 & fermented vinegar; Taiwan \\
\hline & JYC2517 & MK044014 & wine lees; China \\
\hline & JYC2506 & MK044003 & wine; Taiwan \\
\hline & JYC2507 & MK044004 & wine; Taiwan \\
\hline & JYC2508 & MK044005 & wine; Taiwan \\
\hline & JYC2509 & MK044006 & wine; Taiwan \\
\hline & JYC2532 & MK079214 & W303-derivative strain ${ }^{*}$ \\
\hline & JYC2510 & MK044007 & rice wine; Taiwan \\
\hline & JYC2540 & MK044034 & rice wine; Taiwan \\
\hline & JYC2541 & MK044035 & rice wine; Taiwan \\
\hline & JYC2542 & MK044036 & rice wine; Taiwan \\
\hline & JYC2521 & MK044018 & water kefir; Taiwan \\
\hline & JYC2530 & MK044027 & wine; China \\
\hline & JYC2531 & MK044028 & wine; China \\
\hline & JYC2535 & MK044029 & kombucha; Taiwan \\
\hline & JYC2558 & MK044039 & milk kefir; Taiwan \\
\hline & JYC2577 & MK044057 & milk kefir; Israel \\
\hline & JYC2581 & MK044061 & milk kefir; Caucasus \\
\hline & JYC2582 & MK044062 & milk kefir; Caucasus \\
\hline \multirow[t]{6}{*}{ Saccharomycopsis fibuligera } & JYC2511 & MK044008 & wine lees; China \\
\hline & JYC2512 & MK044009 & wine lees; China \\
\hline & JYC2516 & MK044013 & wine lees; China \\
\hline & JYC2518 & MK044015 & wine lees; China \\
\hline & JYC2519 & MK044016 & wine lees; China \\
\hline & JYC2523 & MK044020 & wine lees; China \\
\hline Torulaspora delbrueckii & JYC2520 & MK044017 & water kefir; Taiwan \\
\hline
\end{tabular}




\begin{tabular}{llll}
\hline Wickerhamomyces anomalus & JYC2560 & MK044041 & fermented vinegar; Tawian \\
Zygosaccharomyces bisporus & JYC2526 & MK044023 & coffee beans; Taiwan \\
& JYC2543 & MK044037 & chinese-herbal medicine; Taiwan \\
& JYC2536 & MK044030 & kombucha; Taiwan \\
Zygosaccharomyces rouxii & JYC2561 & MK044042 & fermented vinegar; Taiwan \\
\hline${ }^{*}$ W303 is one laboratory strain that is closely related to the first completely sequenced yeast strain, S288C.
\end{tabular}

Table 1. Antioxidant activity and Trolox equivalents of yeast strains.

\begin{tabular}{|c|c|c|c|}
\hline Percentage & Trolox equivalents & Species & Strain \\
\hline \multirow[t]{2}{*}{$<20 \%$} & From $30.4 \pm 5.4$ to $31.3 \pm 7.9$ & H. osmophila & JYC2504 \\
\hline & & S. cerevisiae & JYC2506, JYC2535 \\
\hline \multirow{4}{*}{$\begin{array}{l}\text { Between } 20 \text { and } \\
30 \%\end{array}$} & From $34.1 \pm 18.5$ to $43 \pm 10.4$ & K. servazzii & JYC2570 \\
\hline & & S. boulardii & I-3799 (New Foods, USA) \\
\hline & & S. cerevisiae & JYC2508, JYC2509, JYC2510 \\
\hline & & W. anomalus & JYC2560 \\
\hline \multirow{7}{*}{$\begin{array}{l}\text { Between } 30 \text { and } \\
40 \%\end{array}$} & From $50.2 \pm 11.2$ to $59.8 \pm 10.9$ & K. exigua & JYC2539, \\
\hline & & K. marxianus & JYC2566, JYC2569 \\
\hline & & K. servazzii & JYC2564, JYC2565, JYC2572 \\
\hline & & K. shandongensis & JYC2515 \\
\hline & & P. kudriavzevii & JYC2527 \\
\hline & & S. cerevisiae & JYC2503, JYC2540, JYC2541 \\
\hline & & S. fibuligera & JYC2518 \\
\hline \multirow[t]{8}{*}{$\begin{array}{l}\text { Between } 40 \text { and } \\
50 \%\end{array}$} & From $62.6 \pm 6.2$ to $79 \pm 5.5$ & K. marxianus & $\begin{array}{l}\text { JYC2528, JYC2557, JYC2563, JYC2575, } \\
\text { JYC2578 }\end{array}$ \\
\hline & & K. servazzii & JYC2568, JYC2571, JYC2574, JYC2583 \\
\hline & & K. turicensis & JYC2529 \\
\hline & & S. cerevisiae & JYC2507, JYC2517, JYC2521, JYC2530, \\
\hline & & & JYC2542, JYC2558 , JYC2531 \\
\hline & & S. fibuligera & JYC2516 \\
\hline & & T. delbrueckii & JYC2520 \\
\hline & & Z. bisporus & JYC2543 \\
\hline \multirow[t]{9}{*}{$>50 \%$} & From $80.6 \pm 3.1$ to $158.2 \pm 5.4$ & D. bruxellensis & JYC2537 \\
\hline & & H. valbyensis & JYC2522 \\
\hline & & K. marxianus & JYC2567, JYC2576 \\
\hline & & K. servazzii & JYC2573, JYC2579, JYC2580 \\
\hline & & K. turicensis & JYC2559 \\
\hline & & S. cerevisiae & JYC2532, JYC2577, JYC2581, JYC2582 \\
\hline & & S. fibuligera & JYC2511, JYC2512, JYC2519, JYC2523 \\
\hline & & Z. bisporus & JYC2526, JYC2536 \\
\hline & & Z. rouxii & JYC2561 \\
\hline
\end{tabular}

\section{DISCUSSION}

Bile salt and acid tolerance: The most essential criterion of any probiotic is the ability to tolerate high acid levels, which are present in the stomach. The hydrochloric acid $(\mathrm{HCl})$ that is found in the human stomach is a strong oxidizer and kills bacteria, protecting the human body from pathogenic microbes that can enter the body through food. $\mathrm{HCl}$ can oxidize fatty acids, proteins, cholesterol, and DNA in cells and disrupt them while it will undergo reduction (Pan et al., 2009). In this in vitro study, the threshold point for determining acid resistance was set at $\mathrm{pH} 3.0$ with an incubation period of $2 \mathrm{~h}$ to simulate the residence time in the stomach (Prasad et al., 1998). This method followed the experimental results from Liong and Shah (Liong and Shah, 2005), who suggested that resistance at $\mathrm{pH} 3$ is a suitable standard for testing the acid tolerance of a probiotic culture. The survival of 
commercial probiotic strains when subjected to low $\mathrm{pH}$ and bile conditions, similar to those present in the human GI tract, should be assessed and substantiated accordingly. Although the concentration of bile in the human GI tract varies, the mean intestinal bile concentration is believed to be $0.3 \% \mathrm{w} / \mathrm{v}$ (Gilliland and Speck, 1977). Upon exposure to bile acids, cellular homeostasis disruptions cause the dissociation of lipid bilayers and the integral proteins in their cell membranes, resulting in the leakage of microbial content and ultimately cell death (Kumura et al., 2004). Of the yeast strains analyzed in the current study, we found that 39 $(65 \%)$ could adapt well to the environment that simulated the human GI tract. Furthermore, we found that five strains adapted well for more than $24 \mathrm{~h}$ to the environment containing bile salt. The strains in this study were subjected to an environment with $0.3 \% \mathrm{w} / \mathrm{v}$ bile salt, which is similar to that in the human gut. Our results showed that most of the strains had better adaptability in this harsh environment than that of the commercialized probiotic yeast $S$. boulardii. Therefore, the yeast strains in this study are worthy of further investigation. The method used in this study only provided partial information about the outcomes of bile exposure (gastric acid). The in vitro conditions that the yeasts were exposed to in this study were not identical to an in situ situation (Guantario et al., 2018). Therefore, the results may not truly reflect how the yeast strains would perform in situ, because many other physiological conditions might affect the survival of the yeast strains. Furthermore, in the human gut, the food matrix protects microorganisms from the deleterious effects of gastric and small intestinal secretions (Begley et al., 2005; Huang and Adams, 2004). Nevertheless, the in vitro bile salt and acid tolerance assay used in this study provides useful information about species and strain differences.

Autoaggregation and cell surface hydrophobicity: Analyses of surface properties, including autoaggregation and cell surface hydrophobicity, both support a probiotic's adherence to epithelial cells (de Lima et al., 2017). The autoaggregation ability of probiotic bacteria correlates with adhesion, which is a prerequisite for colonizing and protecting the GI tract (Kos et al., 2003). Autoaggregation is the reversible accumulation of cells, which causes them to spontaneously precipitate in the medium. Autoaggregation is also affected by different cell wall compositions and the presence of appendages (Touhami et al., 2003) or the amount of adhesins. Cellular aggregates should also be considered when examining the potential of a probiotic, because aggregates can increase a microbe's ability to adhere to the intestine, which is a known prerequisite for colonization and enhanced persistence in the GI system (García-Cayuela et al., 2014). The autoaggregation ability of yeast is better than that of bacteria because their cells are larger and heavier, enabling them to precipitate quicker and in higher proportions. Here we considered an autoaggregation percentage of $80 \%$ before $4 \mathrm{~h}$ at $37{ }^{\circ} \mathrm{C}$ a good threshold for autoaggregation. The results showed that most strains complied with this threshold value, which is consistent with related studies (de Lima et al., 2017; Gil-Rodríguez et al., 2015). Hydrophobicity is likely due to a complex interplay between negatively charged, positively charged, hydrophobic, and hydrophilic components on the surface of microbes. Herein, we report that the yeast isolates showed high cell surface hydrophobicity. This result is consistent with related studies (Syal and Vohra, 2013). The variation in hydrophobicity to solvents has been explained by the fact that adhesion depends on the origin of the strains as well as their surface properties. Cell surface hydrophobicity is affected by the affinity between the cell wall and water and also by the environmental temperature. Blanco et al. (1997) reported that Candida albicans was hydrophobic at $22{ }^{\circ} \mathrm{C}$ and hydrophilic at $37{ }^{\circ} \mathrm{C}$. Probiotics with good autoaggregation ability together with good cell surface hydrophobicity can be strongly related to the adhesion ability of the microorganisms they contain, although these two characteristics are independent (Boirivant and Strober, 2007; Krausova et al., 2019).

Antioxidant activity: Here, the ability of whole cells rather than cell-free extracts from a culture based on DPPH scavenging was assayed. Most of the isolated strains showed good antioxidant activity; 39 strains (66\%) had $\geq 40 \%$ antioxidant activity in $0.2 \mathrm{mM} \mathrm{DPPH}$. Chen et al. (2010a) reported that the antioxidant activity of intact cells is significantly higher than that of their corresponding intracellular cell-free extracts, which was contrary to the properties of lactic acid bacteria (LAB). The antioxidant activity of yeasts is believed to be mainly due to the high amount of $\beta$-glucans found in their cell walls (Abbas, 2006; Jaehrig et al., 2007), as well as other cellular compounds (e.g., superoxide dismutase, glutathione peroxidase, and catalase) (Chen et al., 2010b). Because intact cells show conventionally higher activity than do cell extracts, we propose that other mechanisms may be involved (Naylin et al., 2005). Nevertheless, the antioxidant activity of yeasts seems higher than that of LAB. In our study, the antioxidant activity in TE was generally higher than that reported by Amaretti et al. (2013) for different LAB strains. The mean value of TE obtained for the yeast strains was 68.19 $\mu \mathrm{M}$, whereas a maximum mean value of $158.2 \mu \mathrm{M}$ was obtained for $S$. fibuligera JYC2512. These results are similar to those reported by Gil-Rodríguez et al. who analyzed 130 yeast strains from wine and various foods and found that the activity ranged between $73.39 \pm 0.73$ and $177.60 \pm 0.85 \mu \mathrm{M}$ (Gil-Rodríguez et al., 2015). However, our results (mean $=44.83 \%$ ) are higher than those reported by Chen et al. (2010b) who analyzed intact 
yeast cells collected from raw milk and found that the antioxidant activity ranged from $4.25 \%$ to $46.78 \%$. We found that the strains of $S$. fibuligera had higher antioxidant ability than the other yeast species we isolated. S. fibuligera is usually found worldwide in starchy substrates and is a major amylolytic yeast in indigenous food fermentation. It has recently drawn attention because of its ability to accumulate trehalose when grown on starch (Chi et al., 2009). Trehalose functions as an antioxidant, although its underlying molecular mechanisms remain unclear. The results from the current study suggest that trehalose is able to protect enzymes such as superoxide dismutase, catalase, and ascorbate peroxidase. Trehalose itself plays a key role in directly scavenging $\mathrm{ROS}$, including $\mathrm{O}_{2}^{-}$and $\mathrm{H}_{2} \mathrm{O}_{2}$ and it suggests that trehalose accumulation may play a vital role in the antioxidant activity of $S$. fibuligera and other yeasts (Luo et al., 2008; Zhang et al., 2020).

$\boldsymbol{\beta}$-galactosidase activity: In the current study, the yeast strains that produced $\beta$-galactosidase were all isolated from milk kefir. Most of the isolated strains had higher enzyme activity than that of $S$. cerevisiae, which was isolated from Brazilian kefir-fermented milk (de Lima et al., 2017). The $\beta$-galactosidase activity of the yeast strains in this study ranged from $0.58 \mathrm{U} / \mathrm{mL}$ (11.54 Miller units) to $17.97 \mathrm{U} / \mathrm{mL}$ (113.24 Miller units), but these values were less than those of bifidobacteria (147 to 860 Miller units) and Lactobacillus acidophilus (675 to 1301 Miller units) reported by Vinderola and Reinheimer (2003). These variations observed among yeasts and probiotic bacteria emphasize the importance of selecting appropriate strains for use as dietary adjuvants. Most of the strains with $\beta$-galactosidase activity ( 8 out of 10 strains) in this study belong to $K$. marxianus. Commercial $\beta$-galactosidases are produced from $K$. marxianus and $K$. lactis and molds such as Aspergillus niger and $A$. oryzae (Rosenberg, 2006). Thus, numerous studies have investigated the optimization of $\beta$-galactosidase production and extraction using $K$. marxianus (Bansal et al., 2008; Brady et al., 1995; Martins et al., 2002; Pinheiro et al., 2003; Stred'anský et al., 1993). However, the yeast strains with $\beta$-galactosidase activity in the current study showed a very low tolerance to bile salts. Marteau et al. (1997) stated that a low bile resistance should not be considered a disadvantage for probiotic strains, because intracellular $\beta$-galactosidase or other bioactive compounds might be released from the cells through lysis. Lin et al. (1991) used L. acidophilus strains with varying degrees of resistance to bile and total $\beta$ galactosidase-producing potential to monitor lactose maldigestion by measuring breath hydrogen excretion. They demonstrated that only one strain with low bile resistance and intermediate $\beta$-galactosidase activity was capable of significantly reducing breath hydrogen values. Moreover, Mc Donough et al. (1987) showed that unfermented milk prepared with disrupted cells of $L$. acidophilus improved lactose digestion more effectively than did that prepared with intact cells. By contrast, Zárate et al. (2000) found that the most bile-tolerant propionibacteria strains significantly reduced lactose intolerance symptoms. Noh and Gilliland (1993; 1994) suggested that bile does not cause cell lysis but that bile salts increase cellular permeability and permit more substrates to enter cells to be hydrolyzed. Thus, yeasts with low gastric and small intestine transit tolerance may be essential for in vivo lactose digestion. Because microbial lysis in the small intestine depends on bile salts, intracellular $\beta$-galactosidase might be released from cells through lysis during the passage through the GI tract or, at least, permeabilized cells might be necessary for an efficient lactose hydrolysis to occur in the small intestine (Mustapha et al., 1997). Furthermore, thermostable $\beta$ galactosidases have presently attracted considerable attention because of their significant advantages in processing (Liu et al., 2019). It would be worth considering whether we could use benchtop molecular biology and computer-assisted strategies to improve the thermostability of $\beta$-galactosidases from these candidate yeasts in future investigations.

Conclusions: Probiotics occupy a considerable share in the food and drug industries. The present study focused on expanding the selection of probiotic yeasts from fermented food and beverage. The results showed that the probiotic characteristics and resistance to biological barriers of the isolated yeast strains varied considerable, even among strains belonging to the same species. For example, most strains of $S$. fibuligera had good antioxidant activity and most strains of $K$. marxianus had $\beta$-galactosidase activity and cell surface hydrophobicity. In particular, S. cerevisiae JYC2508 had good results in the assays but not in $\beta$-galactosidase activity, whereas $K$. marxianus JYC2528 had good performance in all the tests and demonstrated good $\beta$-galactosidase activity. Therefore, adequate strain selection should be conducted in future studies to combine different yeasts in foods to evaluate the total "probiotic value" of the starter strains involved. Our findings should encourage further studies on the application of the strains in this study as food and feed supplements. Nevertheless, further investigation is required to confirm their safety.

Acknowledgements: We thank the members of the Chou Lab for their helpful discussion and comments on the manuscript. This work was supported by grants from the Ministry of Science and Technology (MOST 105-2311B-018-001-MY3 to Chou JY). This manuscript was edited by Wallace Academic Editing.

\section{REFERENCES}

Abbas, C.A. (2006). Production of antioxidants, aromas, 
colours, flavours, and vitamins by yeasts. In: Amparo, Q. and H.F. Graham, editors. Yeasts in Food and Beverages (The Yeast Handbook). Springer-Verlag Berlin Heidelberg, Germany, 285-334.

Amaretti, A., M. Di Nunzio, A. Pompei, S. Raimondi, M. Rossi, and A. Bordoni (2013). Antioxidant properties of potentially probiotic bacteria: in vitro and in vivo activities. Appl. Microbiol. Biotechnol., 97: 809-817

Antunes, J. and C. Aguiar (2012). Search for killer phenotypes with potential for biological control. Ann. Microbiol., 62: 427-433

Bansal, S.H., S. Oberoi, G.S. Dhillon, and R. Patil (2008). Production of $\beta$-galactosidase by Kluyveromyces marxianus MTCC 1388 using whey and effect of four different methods of enzyme extraction on $\beta$-galactosidase activity. Indian J. Microbiol., 48: 337-341

Begley, M., C.G. Gahan, and C. Hill (2005). The interaction between bacteria and bile. FEMS Microbiol. Rev., 29: 625-651

Binetti, A., M. Carrasco, J. Reinheimer, and V. Suárez (2013). Yeasts from autochthonal cheese starters: technological and functional properties. J. Appl. Microbiol., 115: 434-444

Blanco, M, J. Blanco, R. Sanchez-Benito, C. PerezGiraldo, F. Moran, C. Hurtado, and A. GomezGarcia (1997). Incubation temperatures affect adherence to plastic of Candida albicans by changing the cellular surface hydrophobicity. Microbios, 89: 23-28

Boirivant, M. and W. Strober (2007). The mechanism of action of probiotics. Curr. Opin. Gastroenterol., 23: 679-692

Brady, D., R. Marchant, L. McHale, and A. McHale (1995). Isolation and partial characterization of $\beta$-galactosidase activity produced by a thermotolerant strain of Kluyveromyces marxianus during growth on lactose-containing media. Enzyme Microb. Technol., 17: 696-699

Chen, L.S., Y. Ma, L.J. Chen, C.H. Zhao, J.L. Maubois, T.M. Jiang, H.M. Li, and S.H. He (2010a). Antioxidant activity of two yeasts and their attenuation effect on 4-nitroquinoline 1-oxide induced in vitro lipid peroxidation. Int. J. Food Sci. Technol., 45: 555-561

Chen, L.S., Y. Ma, J.L. Maubois, L.J. Chen, Q.H. Liu, and J.P. Guo (2010b). dentifcation of yeasts from raw milk and selection for some specific antioxidant properties. Int. J. Dairy Technol., 63: $47-54$

Cheung, S., A. R. Goldenthal, A. C. Uhlemann, J. J. Mann, J. M. Miller and M. E. Sublette (2019). Systematic review of gut microbiota and major depression. Front. Psychiatry, 10: 34
Chi, Z., Z. Chi, G. Liu, F. Wang, L. Ju, and T. Zhang (2009). Saccharomycopsis fibuligera and its applications in biotechnology. Biotechnol. Adv., 27: 423-431

Ciafardini, G., and B. A. Zullo (2020). In vitro potential antioxidant activity of indigenous yeasts isolated from virgin olive oil. J. Appl. Microbiol., 128: 853-861

Czerucka, D., T. Piche, and P. Rampal (2007). yeast as probiotics-Saccharomyces boulardii. Aliment. Pharmacol. Ther., 26: 767-778

Czerucka, D. and P. Rampal (2002). Experimental effects of Saccharomyces boulardii on diarrheal pathogens. Microbes Infect., 4: 733-739

de Lima, M.D.S.F., K.M.S. de Souza, W.W.C. Albuquerque, J.A.C. Teixeira, M.T.H. Cavalcanti, and A.L.F. Porto (2017). Saccharomyces cerevisiae from Brazilian kefirfermented milk: An in vitro evaluation of probiotic properties. Microb. Pathog., 110: 670677

De Vrese, M. and J. Schrezenmeir (2008). Probiotics, prebiotics, and synbiotics. Adv. Biochem. Eng. Biotechnol., 111: 1-66

Diosma, G., D.E. Romanin, M.F. Rey-Burusco, A. Londero, and G.L. Garrote (2014). Yeasts from kefir grains: isolation, identification, and probiotic characterization. World J. Microbi. Biot., 30: 43-53

Eckburg, P.B., E.M. Bik, C.N. Bernstein, E. Purdom, L. Dethlefsen, M. Sargent, S.R. Gill, K.E. Nelson, and D.A. Relman (2005). Diversity of the human intestinal microbial flora. Science, 308: $1635-1638$

Food and Agriculture Organization of the United Nations/World Health Organization FAO/WHO Health and Nutritional Properties of Probiotics in Food including Powder Milk with Live Lactic Acid Bacteria (2001). [(accessed on 20 January 2014)]. Available online: http://www.who.int/foodsafety/publications/fs management/en/probiotics.pdf.

Food and Agriculture Organization of the United Nations/World Health Organization FAO/WHO. Guidelines for the Evaluation of Probiotics in Food. Joint FAO/WHO Working Group on Drafting Guidelines for the Evaluation of Probiotics in Food; London, Ontario, Canada: (2002).

García-Cayuela, T., A.M. Korany, I. Bustos, L.P.G. de Cadiñanos, T. Requena, C. Peláez, and M.C. Martínez-Cuesta (2014). Adhesion abilities of dairy Lactobacillus plantarum strains showing an aggregation phenotype. Food Res. Int., 57: $44-50$

Gil-Rodríguez, A.M., A.V. Carrascosa, and T. Requena 
(2015). Yeasts in foods and beverages: In vitro characterisation of probiotic traits. LWT-Food Sci. Technol., 64: 1156-1162

Gilliland, S. and M. Speck (1977). Use of the Minitek system for characterizing lactobacilli. Appl. Environ. Microbiol., 33: 1289-1292

Guantario, B., P. Zinno, E. Schifano, M. Roselli, G. Perozzi, C. Palleschi, D. Uccelletti, and C. Devirgiliis (2018). In vitro and in vivo selection of potentially probiotic lactobacilli from Nocellara del Belice table olives. Front. Microbiol., 9: 595

Heijtz, R.D., S. Wang, F. Anuar, Y. Qian, B. Björkholm, A. Samuelsson, M.L. Hibberd, H. Forssberg, and S. Pettersson (2011). Normal gut microbiota modulates brain development and behavior. Proc. Natl. Acad. Sci. USA, 108: 3047-3052

Hertzler, S.R.S.M. and S.M. Clancy (2003). Kefir improves lactose digestion and tolerance in adults with lactose maldigestion. J. Acad. Nutr. Diet., 103: 582-587

Hill, C., F. Guarner, G. Reid, G.R. Gibson, D.J. Merenstein, B. Pot, L. Morelli, R.B. Canani, H.J. Flint, and S. Salminen (2014). Expert consensus document: The International Scientific Association for Probiotics and Prebiotics consensus statement on the scope and appropriate use of the term probiotic. Nat. Rev. Gastroenterol. Hepatol., 11: 506-514

Huang, Y. and M.C. Adams (2004). In vitro assessment of the upper gastrointestinal tolerance of potential probiotic dairy propionibacteria. Int. J. Food Microbiol., 91: 253-260

Jaehrig, S.C., S. Rohn, L.W. Kroh, L.G. Fleischer, and T. Kurz (2007). In vitro potential antioxidant activity of $(1 \rightarrow 3),(1 \rightarrow 6)-\beta$-d-glucan and protein fractions from Saccharomyces cerevisiae cell walls. J. Agric. Food Chem., 55: 4710-4716

Kau, A.L., P.P. Ahern, N.W. Griffin, A.L. Goodman, and J.I. Gordon (2011). Human nutrition, the gut microbiome and the immune system. Nature, 474: $327-336$

Kawagishi, H. and T. Finkel (2014). Unraveling the truth about antioxidants: ROS and disease: finding the right balance. Nat. Med., 20: 711-713

Kippert, F. (1995). A rapid permeabilization procedure for accurate quantitative determination of $\beta$ galactosidase activity in yeast cells. FEMS Microbiol. Rev., 128: 201-206

Kos, B., J. Šušković, S. Vuković, M. Šimpraga, J. Frece, and S. Matošić (2003). Adhesion and aggregation ability of probiotic strain Lactobacillus acidophilus M92. J. Appl. Microbiol., 94: 981-987

Krausova, G., I. Hyrslova and I. Hynstova (2019). In vitro evaluation of adhesion capacity, hydrophobicity, and auto-aggregation of newly isolated potential probiotic strains. Fermentation, 5: 100

Kumura, H., Y. Tanoue, M. Tsukahara, T. Tanaka, and K. Shimazaki (2004). Screening of dairy yeast strains for probiotic applications. J. Dairy Sci., 87: 4050-4056

Kurtzman, C. and C. Robnett (1997). Identification of clinically important ascomycetous yeasts based on nucleotide divergence in the 5 'end of the large-subunit (26S) ribosomal DNA gene. $J$. Clin. Microbiol., 35: 1216-1223

Lin, M.Y., D. Savaiano, and S. Harlander (1991). Influence of Nonfermented Dairy Products Containing Bacterial Starter Cultures on Lactose Maldigestion in Humans1. J. Dairy Sci., 74: 8795

Liong, M. and N. Shah (2005). Acid and bile tolerance and cholesterol removal ability of lactobacilli strains. J. Dairy Sci., 88: 55-66

Liu, P., J. Xie, J. Liu, and J. Ouyang (2019). A novel thermostable $\beta$-galactosidase from Bacillus coagulans with excellent hydrolysis ability for lactose in whey. J. Dairy Sci., 102: 9740-9748

Long-Smith, C., K. J. O'Riordan, G. Clarke, C. Stanton, T. G. Dinan, and J. F. Cryan (2020). MicrobiotaGut-Brain Axis: New Therapeutic Opportunities. Annu. Rev. Pharmacol. Toxicol., 60: 477-502

Luo, Y., W.M. Li, and W. Wang (2008). Trehalose: protector of antioxidant enzymes or reactive oxygen species scavenger under heat stress? Environ. Exper. Bot., 63: 378-384

Marteau, P., M. Minekus, R. Havenaar, and J. Huis (1997). Survival of lactic acid bacteria in a dynamic model of the stomach and small intestine: validation and the effects of bile. $J$. Dairy Sci., 80: 1031-1037

Martins, D.B.G., C.G. de Souza Jr., D.A. Simoes, and M.A. de Morais Jr. (2002). The $\beta$-galactosidase activity in Kluyveromyces marxianus CBS6556 decreases by high concentrations of galactose. Curr. Microbiol., 44: 379-382

Mathur, S. and R. Singh (2005). Antibiotic resistance in food lactic acid bacteria-a review. Int. J. Food Microbiol., 105: 281-295

Mayer, E.A. (2011). Gut feelings: the emerging biology of gut-brain communication. Nat. Rev. Neurosci. 12:453-466

McDonough, F.E., A.D. Hitchins, N.P. Wong, P. Wells, and C. Bodwell (1987). Modification of sweet acidophilus milk to improve utilization by lactose-intolerant persons. Am. J. Clin. Nutr., 45: $570-574$

Miller, J (1972). Experiments in Molecular Genetics. Cold Spring Harbor Laboratory, New York, USA, 352-355 
Miller, R., A. Hoffmann, R. Hartmann, K.H. Schano, and A. Halbig (1992). Measuring dynamic surface and interfacial tensions. Adv. Mater. 4: 370-374

Moreira, N, C. Pina, F. Mendes, J. Couto, T. Hogg, and I. Vasconcelos (2011). Volatile compounds contribution of Hanseniaspora guilliermondii and Hanseniaspora uvarum during red wine vinifications. Food Control, 22: 662-667

Mustapha, A., T. Jiang, and D.A. Savaiano (1997). Improvement of lactose digestion by humans following ingestion of unfermented acidophilus milk: influence of bile sensitivity, lactose transport, and acid tolerance of Lactobacillus acidophilus. J. Dairy Sci., 80: 1537-1545

Naylin, N., O. Taing, F. Hashinaga, and Y. Toshima (2005). Antioxidant activity of sugar-tolerant yeast Zygosaccharomyces rouxii. Food Biotechnol., 19: 107-120

Noh, D. and S. Gilliland (1994). Influence of Bile on $\beta$ Galactosidase Activity of Component Species of Yogurt Starter Cultures. J. Dairy Sci., 77: 35323537

Noh, D.O. and S. Gilliland (1993). Influence of Bile on Cellular Integrity and $\beta$-Galactosidase Activity of Lactobacillus acidophilus. J. Dairy Sci., 76: 1253-1259

Ogunremi, O.R., A.I. Sanni, and R. Agrawal (2015). Probiotic potentials of yeasts isolated from some cereal-based Nigerian traditional fermented food products. J. Appl. Microbiol., 119: 797-808

Ofek, I. and E.H. Beachey (1978). Mannose binding and epithelial cell adherence of Escherichia coli. Infect. Immun., 22: 247-254

Pan, X., F. Chen, T. Wu, H. Tang, and Z. Zhao (2009). The acid, bile tolerance and antimicrobial property of Lactobacillus acidophilus NIT. Food Control, 20: 598-602

Perricone, M., A. Bevilacqua, M.R. Corbo, and M. Sinigaglia (2014). Technological characterization and probiotic traits of yeasts isolated from Altamura sourdough to select promising microorganisms as functional starter cultures for cereal-based products. Food Microbiol., 38: 26-35

Pinheiro, R., I. Belo, and M. Mota (2003). Growth and $\beta$ galactosidase activity in cultures of Kluyveromyces marxianus under increased air pressure. Lett Appl. Microbiol., 37: 438-442

Prasad, J., H. Gill, J. Smart, and P.K. Gopal (1998). Selection and characterisation of Lactobacillus and Bifidobacterium strains for use as probiotics. Int. Dairy J., 8: 993-1002

Rima, H., L. Steve, and F. Ismail (2012). Antimicrobial and probiotic properties of yeasts: from fundamental to novel applications. Front. Microbiol., 3: 421
Romero-Luna, H.E., H. Hernández-Sánchez, R.M. RibasAparicio, P.I. Cauich-Sánchez, and G. DávilaOrtiz (2019). Evaluation of the probiotic potential of Saccharomyces cerevisiae strain (C41) isolated from tibicos by in vitro studies. Probiotics Antimicrob. Proteins, 11: 794-800

Rosenberg, M., D. Gutnick, and E. Rosenberg (1980). Adherence of bacteria to hydrocarbons: a simple method for measuring cell-surface hydrophobicity. FEMS Microbiol. Lett., 9: 2933

Rosenberg, Z.M.M. (2006). Current trends of $\beta$ galactosidase application in food technology. $J$. Food Nutr. Res., 45: 47-54

Salyers, A.A., A. Gupta, and Y. Wang (2004). Human intestinal bacteria as reservoirs for antibiotic resistance genes. Trends Microbiol., 12: 412 416

Saqib, S., A. Akram, S.A. Halim, and R. Tassaduq (2017). Sources of $\beta$-galactosidase and its applications in food industry. 3 Biotech 7:79

Serafini, M. (2006). The role of antioxidants in disease prevention. Medicine, 34: 533-535

Silva, T., M. Reto, M. Sol, A. Peito, C. Peres, C. Peres, and F.X. Malcata (2011). Characterization of yeasts from Portuguese brined olives, with a focus on their potentially probiotic behavior. LWT-Food Sci. Technol., 44: 1349-1354

Sourabh, A., S.S. Kanwar, and O.P. Sharma (2011). Screening of indigenous yeast isolates obtained from traditional fermented foods of Western Himalayas for probiotic attributes. J. Yeast Fungal Res., 2: 117-126

Stred'anský, M., M. Tomáška, E. Šturdík, and L. Kremnický (1993). Optimization of $\beta$ galactosidase extraction from Kluyveromyces marxianus. Enzyme Microb. Technol., 15: 10631065

Syal, P. and A. Vohra (2013). Probiotic potential of yeasts isolated from traditional Indian fermented foods. Int. J. Microbiol. Res., 5: 390-398

Temmerman, R., B. Pot, G. Huys, and J. Swings (2003). Identification and antibiotic susceptibility of bacterial isolates from probiotic products. Int. J. Food Microbiol., 81: 1-10

Terpou, A., A. Papadaki, I. L. Lappa, V. Kachrimanidou, L. A. Bosnea, and N. Kopsahelis (2019). Probiotics in food systems: significance and emerging strategies towards improved viability and delivery of enhanced beneficial value. Nutrients, 11: 1591

Touhami, A., B. Hoffmann, A. Vasella, F. A. Denis, and Y. F. Dufrêne (2003). Aggregation of yeast cells: direct measurement of discrete lectincarbohydrate interactions. Microbiology, 149: 2873-2878 
Tripathi, M. and S. Giri (2014). Probiotic functional foods: Survival of probiotics during processing and storage. J. Funct. Foods, 9: 225-241

Trotta, F., G. Caldini, L. Dominici, E. Federici, R. Tofalo, M. Schirone, A. Corsetti, G. Suzzi, and G. Cenci (2012). Food borne yeasts as DNA-bioprotective agents against model genotoxins. Int. J. Food Microbiol., 153: 275-280

Valko, M., C. Rhodes, J. Moncol, M. Izakovic, and M. Mazur (2006). Free radicals, metals and antioxidants in oxidative stress-induced cancer. Chem.-Biol. Interact., 160: 1-40

Van der Aa Kühle, A, K. Skovgaard, and L. Jespersen (2005). In vitro screening of probiotic properties of Saccharomyces cerevisiae var. boulardii and food-borne Saccharomyces cerevisiae strains. Int. J. Food Microbiol., 101: 29-39

Vinderola, C. and J. Reinheimer (2003). Lactic acid starter and probiotic bacteria: a comparative "in vitro" study of probiotic characteristics and biological barrier resistance. Food Res. Int., 36: 895-904

White, T.J., T. Bruns, S. Lee, and J.W. Taylor (1990). Amplification and direct sequencing of fungal ribosomal RNA genes for phylogenetics. In: PCR protocols: a guide to methods and applications, pp: 315-322. Innis, M.A, D.H. Gelfand, J.J. Sninsky, T.J. White (eds.). Academic Press, New York, USA

Zárate, G., A.P. Chaia, S. González, and G. Oliver (2000). Viability and $\beta$-galactosidase activity of dairy propionibacteria subjected to digestion by artificial gastric and intestinal fluids. J. Food Prot., 63: 1214-1221

Zhang, X., Y. Zhang, and H. Li (2020). Regulation of trehalose, a typical stress protectant, on central metabolisms, cell growth and division of Saccharomyces cerevisiae CEN. PK113-7D. Food Microbiol., 89: 103459. 